\title{
Significance of Personal Exposure Assessment to Air Pollution in the Urban Areas of Egypt
}

\author{
Mahmoud M. M. Abdel-Salam \\ Department of Environmental Sciences, Faculty of Science, Alexandria University, Alexandria, Egypt \\ Email: $\underline{\text { m.abdsalam@gmail.com }}$
}

Received 16 January 2015; accepted 3 February 2015; published 6 February 2015

Copyright (c) 2015 by author and Scientific Research Publishing Inc.

This work is licensed under the Creative Commons Attribution International License (CC BY).

http://creativecommons.org/licenses/by/4.0/

(c) () Open Access

\begin{abstract}
Air pollution, both indoor and outdoor, has been found to be related to serious adverse health effects. Accurate estimation of air pollution exposure has become very important to suggest proper air pollution control policies and to further assess the effectiveness of these policies. In many instances, personal exposures have been found to be greater than concentrations measured at fixed site monitoring stations. As people spend most of their time indoors particularly during harsh weather conditions, it is necessary to consider indoor air quality in exposure assessment studies. The current paper focuses on the importance of personal exposure assessment based on spatial and temporal activity patters both indoors and outdoors.
\end{abstract}

\section{Keywords}

\section{Air Pollution, Personal Exposure, Health Effects, Exposure Assessment}

\section{Introduction}

A primary goal of air pollution control policy is to reduce, or ideally eliminate adverse effects on human health. It is well known that health risk assessment is most effective as a policy tool when it is linked to realistic exposure assessment, rather than to environmental concentrations. This is because exposure (defined in the context of this application as direct contact between an air pollutant and a human being [1]) is likely to be more closely related to health effects experienced by individuals. However, many study designs used in time series studies of health effects, and hence in assessing the health benefits of emission reductions, relied on air pollution concentrations measured at fixed measurement stations, usually at urban background sites, to define exposure of the study populations [2]-[4]. However, it is well established by extensive modeling and measurement studies that 
these concentrations cannot represent actual population exposures, because of the huge temporal and spatial variation in human activities [5] [6]. This creates significant difficulties in establishing the real health benefits of policies designed to meet ambient air quality standards which are based on these time series studies [7].

The development of air pollution control policy requires accurate assessment of the impacts of current concentrations, and of the potential benefits of measures to reduce current emissions. In the case of human health, a key element of any such assessment is an estimate of the actual exposure of individuals to specific pollutants. While the measurement of air pollution is usually based on the use of fixed site monitors, the mobility of individuals means that their actual exposure will vary over the course of a day, as they move among locations such as home, street, office, car, etc. This interaction between the spatial and temporal variation in pollutant concentration and the time-activity patterns of individual people means that almost every individual will have a unique personal exposure to air pollution (i.e. unique concentration profile). For example, [8] found that the individual exposure to particulate matter of diameter less than $10 \mu \mathrm{m}\left(\mathrm{PM}_{10}\right)$ of a small group of traffic wardens differed by a factor of 5. The rapid changes in concentration as the individual moves from one location to another may have health significance. Also, cumulative exposure, or average exposure over certain fixed time intervals may be more important considerations.

There is a well-established association between ambient air pollution and adverse health outcomes in developed and developing countries [9]-[13]. The probability of adverse health outcomes will be greater in those individuals with higher exposure. In most urban cities, the highest outdoor concentrations are found at roadside sites, and thus the greatest health benefits may appear to arise from measures which reduce roadside concentrations. Indeed, there is evidence in many studies that the greater exposure to air pollutants of individuals living close to roads is associated with a greater prevalence of respiratory symptoms [14]-[16]. For example, different studies in the US and Europe have reported significant associations between daily mortality and $\mathrm{PM}_{10}$ [17]-[19]. It has been found that both respiratory and cardiovascular diseases are the major causes of death. Many studies have also shown positive associations between daily $\mathrm{PM}_{10}$ concentrations and daily hospital admissions for respiratory diseases (e.g. asthma, pneumonia, chronic obstructive pulmonary disease (COPD), etc.) [20] [21]. Other studies have reported increased hospital admissions for cardiovascular diseases (e.g. congestive heart failure, increase in coronary artery disease, etc.) associated with increased particle concentrations [22].

However, evaluation of the significance of such health effects within the wider urban population depends critically on how roadside concentrations at specific sites actually relate to population-scale exposures. While ambient air quality data from individual urban background monitoring stations are typical of significant areas of cities, a major problem in the interpretation of data from roadside stations is that they are heavily influenced by the characteristics of local traffic flow. This means that it is problematic to use data from such sites in population-based estimates of impacts on personal exposure and health outcomes. Furthermore, people spend most of their time indoors particularly for groups such as elderly or those with pre-existing disease. Therefore, it is essential for estimates of population exposure that the relationships between indoor and ambient concentrations at both roadside and urban background sites are considered. Previous studies clearly show that even at roadside sites, indoor concentrations are substantially modified by the effect of indoor sources [23]-[25].

Direct personal measurement and the use of diaries by participants can be used to estimate exposure and indeed to demonstrate closer links of health effects to exposure than to outdoor concentrations [26]. Methods of measuring individual pollutant exposure include personal (direct) method and microenvironmental (indirect) method. Personal monitoring involves attaching a monitor to an individual. The microenvironmental approach involves measuring pollutant concentrations in a number of defined environments in which an individual spends time, and combining these measurements with information on the person's time-activity pattern to estimate their exposure. Both personal and semi-portable background monitors may be used to estimate pollutant concentrations in the various environments. Personal sampling is the most reliable means of assessing true exposure and it is used to evaluate as accurately as possible an individual's exposure to air pollutants. Exposure measurements are particularly important in both workplace environments and in recent studies of air pollution exposures [27][36]. Information on the person's time-activity pattern can also be collected in order to interpret the person's exposure profile. Time-activity data (e.g. time spent commuting to and from work, mode of transport, smoking characteristics, etc.) may be collected by direct observation, by the use of self-administered daily time-activity diaries, or by questionnaires. However, when considering air pollution control policy over a nation, a region or a city, it is necessary to consider the exposure of the population as a whole. If the objective is to interpret population-based studies or to estimate health effects or health benefits across a population, then this direct approach is 
not possible, and the only practical approach to estimating exposure across the population, rather than individuals, is through appropriate computer models.

The nature of an individual's or a population's behavior, in terms of spatial and temporal activity patters, is a crucial determinant of their personal exposure to air pollutants. Because personal exposure assessment is concerned with the exposure to a single pollutant at the level of the individual, any pollutant monitoring exercise must incorporate the spatial and temporal variables associated with both individuals and pollutants. The exposure to any one pollutant will vary markedly depending on the location, characteristics of that location, activities undertaken, time of day or season, and the actual time spent in that location [37]. In many cases, personal exposures have been found to be greater than concentrations measured at fixed site monitoring stations [27] [38][40].

While the development of personal exposure assessment methodologies has been a key element of research in the US over the past three decades, it has received little or no attention in most developing countries as Egypt. Personal exposure assessment is the only basis on which the health effects of air pollutants on individuals or populations can properly be assessed. The results of personal exposure assessment have often provided new thoughts into the importance of different sources of exposure, which are significant in terms of developing effective control strategies. For example, [41] estimated that, for benzene, 50\% of the population exposure was due to direct smoking, $25 \%$ was due to personal activities such as passive smoking, car driving and the use of certain consumer products, and only $15 \%$ due to direct outdoor exposure. Thus, measures to reduce outdoor concentrations may have rather limited impact on population exposure, unless they are accompanied by measures to reduce the other sources of exposure. Also, US studies of personal exposure to CO have suggested that the most important element of exposure is that within vehicles; this may also be an important source of exposure to other pollutants, such as benzene and other VOCs [42].

Exposure assessment can help us to determine what, where, and when pollutants come in contact with humans. The assessment of personal exposure is also of critical importance in terms of objectively assessing the relative benefits of different pollution control policies [43]. Unless the relative importance of exposure in different locations can be evaluated, it is impossible to properly assess the implications of policies to reduce exposure in individual locations. As Egypt has promulgated ambient air quality standards established by the Egyptian Environmental Law No. 4, 1994, and developed policies to meet these standards to protect public health, it is essential that the benefits of these policies for personal exposure can be properly assessed. The current procedures of comparing concentrations at fixed site monitoring stations with these standards, or estimating the number of people living in areas with particular pollutant concentrations are clearly inadequate for this purpose.

\section{Methodology and Significance}

A series of exposure assessment studies are to be conducted in Egypt to quantify and assess exposure of different groups of people including both normal and sensitive (e.g., children and elderly) groups to air pollutants. This will identify activities and microenvironments that contribute most to daily exposures of participants. Personal exposure will be measured in the different locations in which people spend time such as homes, cars, offices, schools, elderly care centers, etc. Personal monitors of particulate matter $\left(\mathrm{PM}_{10}\right.$ and $\left.\mathrm{PM}_{2.5}\right)$ and gaseous air pollutants known to cause adverse health effects (e.g. $\mathrm{CO}, \mathrm{NO}_{2}$, VOCs, etc.) will be used to continuously measure personal exposure by either direct attachment to participants or being placed in different microenvironments. Electronic diaries will be used to determine time-activity patterns and exposure profiles of all subjects. Conducting the studies in different areas and seasons will demonstrate the temporal and spatial variation of exposure levels of different groups. Outdoor air quality data will be collected to assess how personal exposures differ from outdoor concentrations and that the impacts of air pollution on an individual's health actually relate not to these outdoor concentrations but to their personal exposure.

It is highly expected to find a wide variation in personal exposure among different groups as well as individuals of the same groups as a result of different indoor and outdoor emission sources and activity patterns. Identifying groups of people with high personal exposure and their underlying causes is particularly important in Egypt where emission levels are high, but there are limited resources for environmental and health protection. This can identify a wider range of policy measures to significantly reduce exposure of such groups than direct emission control. As the science of personal exposure assessment has increasingly developed in North America and Western Europe, there is an urgent need to apply this science, with the associated measurement and model- 
ing techniques, in other countries where the impacts of air pollution are much more serious. The aims of the current paper are to emphasize the significance of the followings:

1) Introduce and establish a personal exposure assessment strategy using direct measurement (i.e. personal sampling technique) and indirect methods (i.e. microenvironmental method) as the only basis on which the health effects of air pollutants on individuals or populations can reliably be assessed;

2) Properly evaluate personal exposure in different locations (both indoors and outdoors) to air pollutants and thus to accurately assess current policies which are used to reduce emissions in different sectors in terms of their impacts on human health, i.e. objectively assessing the relative benefits of different pollution control policies;

3) Select and develop the most effective air pollution control strategies that can significantly reduce exposure to air pollutants;

4) Construct a database of personal exposure measurements that is useful in estimating exposure across the population through appropriate computer models;

5) Set proper air quality standards, both indoor and outdoor, according to the accurate and reliable estimates of personal exposure as well as the related health impacts;

6) Assist in advising national, regional and local government in developing stringent policies and actions that will reduce urban air pollution.

In the light of all of the above, this will help to introduce and establish the process of personal exposure assessment to air pollution in Egypt as an effective tool and the only basis on which the health effects of air pollutants on individuals and population can properly be assessed. Also, this will enhance our knowledge about the pattern of human exposures in Egypt, particularly in urban areas where high concentrations of air pollutants and related health impacts always exist. This will help to save and protect human health through the development of effective air pollution control strategies and also contribute to raise awareness of the public regarding exposure assessment through their potential participation as volunteers in related procedures.

\section{References}

[1] Zartarian, V.G., Ott, W.R. and Duan, N. (1997) A Quantitative Definition of Exposure and Related Concepts. Journal of Exposure Analysis and Environmental Epidemiology, 7, 411-438.

[2] Katsouyanni, K., Schwartz, J., Spix, C., Touloumi G., Zxirou, D., Zanobetti, A., Wojtyniak, B., Vonk, J.M., Tobias, A., Ponka, A., Medina, S., Bacharova, L. and Anderson, H.R. (1996) Short Term Effects of Air Pollution on Health: A European Approach Using Epidemiologic Time Series Data: The APHEA Protocol. Journal of Epidemiology and Community Health, 50, S12-S18. http://dx.doi.org/10.1136/jech.50.Suppl 1.S12

[3] Schwartz, J., Spix, C., Touloumi G., Bacharova, L., Barumamdzadeh, T., le Tetre, A., Tierkarski, T., Ponce de Leon, A., Ponka, A., Rossi, G., Saez, M. and Schouten, J.P. (1996) Methodological Issues in Studies of Air Pollution and Daily Counts of Deaths or Hospital Admissions. Journal of Epidemiology and Community Health, 50, S3-S11. http://dx.doi.org/10.1136/jech.50.Suppl 1.S3

[4] Atkinson, R.W., Anderson, H.R., Strachan, D.P., Bland, J.M., Bremner, S.A. and de Leon, A.P. (1999) Short Term Associations between Emergency Hospital Admissions for Respiratory and Cardiovascular Disease and Outdoor Pollution in London. Archives of Environmental Health, 54, 398-411. http://dx.doi.org/10.1080/00039899909603371

[5] Wallace, L.A. (1995) Human Exposure to Environmental Pollutants: A Decade of Experience. Clinical and Experimental Allergy, 25, 4-9. http://dx.doi.org/10.1111/j.1365-2222.1995.tb00996.x

[6] Violante, F.S., Barbieri, A., Curti, S., Sanguinetti, G., Graziosi, F. and Mattioli, S. (2006) Urban Atmospheric Pollution: Personal Exposure versus Fixed Monitoring Station Measurements. Chemosphere, 64, 1722-1729. http://dx.doi.org/10.1016/j.chemosphere.2006.01.011

[7] Bahadori, T., Suh, H. and Koutrakis, P. (1999) Issues in Human Particulate Exposure Assessment: Relationship between Outdoor, Indoor and Personal Exposures. Human and Ecological Risk Assessment, 5, 459-470. http://dx.doi.org/10.1080/10807039.1999.10518871

[8] Watt, M., Godden, D., Cherrie, J. and Seaton, A. (1995) Individual Exposure to Particulate Air Pollution and Its Relevance to Thresholds for Health Effects. Occupational and Environmental Medicine, 52, 790-792. http://dx.doi.org/10.1136/oem.52.12.790

[9] Dockery, D.W., Pope, C.A., Xu, X., Spengler, J.D., Ware, J.H., Fay, M.E., Ferris, B.G. and Speizer, F.E. (1993) An Association between Air Pollution and Mortality in Six U.S. Cities. New England Journal of Medicine, 329, 1753-1759. http://dx.doi.org/10.1056/NEJM199312093292401

[10] Schwartz, J. (1994) Air Pollution and Daily Mortality: A Review and Meta Analysis. Environmental Research, 64, 36- 


\section{2. http://dx.doi.org/10.1006/enrs.1994.1005}

[11] WHO (2001) World Health Report. World Health Organization, Geneva.

[12] WHO (2002) World Health Report: Reducing Risks, Promoting Healthy Life. World Health Organization, Geneva.

[13] Pope, C.A. and Dockery, D.W. (2006) Health Effects of Fine Particulate Air Pollution: Lines that Connect. Journal of the Air \& Waste Management Association, 56, 709-742. http://dx.doi.org/10.1080/10473289.2006.10464485

[14] Van Vliet, P., Knape, M., de Hartog, J., Janssen, N.A.H., Harssema, H. and Brunekreef, B. (1997) Air Pollution from Road Traffic and Chronic Respiratory Symptoms in Children Living near Motorways. Environmental Research, 74, 122-132. http://dx.doi.org/10.1006/enrs.1997.3757

[15] Ciccone, G., Forastiere, F., Agabiti, N., Biggeri, A., Bisanti, L., Chellini, E., Corbo, G., Dell'Orco, V., Dalmasso, P., Volante, T.F., Galassi, C., Piffer, S., Renzoni, E., Rusconi, F., Sestini, P. and Viegi, G. (1998) Road Traffic and Adverse Respiratory Effects in Children. Occupational and Environmental Medicine, 55, 771-778. http://dx.doi.org/10.1136/oem.55.11.771

[16] Kramer, U., Koch, T., Ranft, U., Ring, J. and Behrendt, H. (2000) Traffic-Related Air Pollution Is Associated with Atopy in Children Living in Urban Areas. Epidemiology, 11, 64-70.

http://dx.doi.org/10.1097/00001648-200001000-00014

[17] Schwartz, J. (1993) Air Pollution and Daily Mortality in Birmingham, Alabama. American Journal of Epidemiology, 137, 1136-1147.

[18] Verhoeff, A.P., Hoek, G., Schwartz, J. and van Wijuen, J.H. (1996) Air Pollution and Daily Mortality in Amsterdam, the Netherlands. Epidemiology, 7, 225-230. http://dx.doi.org/10.1097/00001648-199605000-00002

[19] Janssen, N.A.H., Fischer, P., Marra, M., Ameling, C. and Cassee, F.R. (2013) Short-Term Effects of $\mathrm{PM}_{2.5}, \mathrm{PM}_{10}$ and $\mathrm{PM}_{2.5-10}$ on Daily Mortality in the Netherlands. Science of the Total Environment, 464, 20-26. http://dx.doi.org/10.1016/j.scitotenv.2013.05.062

[20] Schwartz, J., Slater, D., Larson, T.V., Pierson, W.E. and Koenig, J.Q. (1993) Particulate Air Pollution and Hospital Emergency Room Visits for Asthma in Seattle. American Review of Respiratory Disease, 147, 826-831. http://dx.doi.org/10.1164/ajrccm/147.4.826

[21] Dockery, D.W. and Pope, C.A. (1994) Acute Respiratory Effects of Particulate Air Pollution. Annual Review of Public Health, 15, 107-132. http://dx.doi.org/10.1146/annurev.pu.15.050194.000543

[22] Schwartz, J. and Morris, R. (1995) Air Pollution and Hospital Admissions for Cardiovascular Disease in Detroit, Michigan. American Journal of Epidemiology, 142, 23-35.

[23] Jones, N.C., Thornton, C.A., Mark, D. and Harrison, R.M. (2000) Indoor/Outdoor Relationships of Particulate Matter in Domestic Homes with Roadside, Urban and Rural Locations. Atmospheric Environment, 34, 2603-2612. http://dx.doi.org/10.1016/S1352-2310(99)00489-6

[24] Abdel-Salam, M.M. (2012) Indoor Particulate Matter in Different Residential Areas of Alexandria City, Egypt. Indoor \& Built Environment, 21, 857-862. http://dx.doi.org/10.1177/1420326X11422262

[25] Abdel-Salam, M.M. (2013) Indoor Particulate Matter in Urban Residences of Alexandria, Egypt. Journal of the Air \& Waste Management Association, 63, 956-962. http://dx.doi.org/10.1080/10962247.2013.801374

[26] Seaton, A., Soutar, A., Crawford, V., Elton, R., McNerlan, S., Cherrie, J., Watt, M., Agius, R. and Stout, R. (1999) Particulate Air Pollution and the Blood. Thorax, 54, 1027-1032. http://dx.doi.org/10.1136/thx.54.11.1027

[27] Spengler, J.D., Treitman, R.D., Tosteson, T.D., Mage, D.T. and Soczek, M.L. (1985) Personal Exposures to Respirable Particulates and Implications for Air Pollution Epidemiology. Environmental Science and Technology, 19, $700-707$. http://dx.doi.org/10.1021/es00138a008

[28] Wallace, L. (1993) A Decade of Studies of Human Exposure: What Have We Learned. Risk Analysis, 13, $135-139$. http://dx.doi.org/10.1111/j.1539-6924.1993.tb01059.x

[29] Chan, L.Y., Kwok, W.S. and Chan, C.Y. (2000) Human Exposure to Respirable Suspended Particulate and Airborne Lead in Different Roadside Microenvironments. Chemosphere, 41, 93-99. http://dx.doi.org/10.1016/S0045-6535(99)00394-X

[30] Janssen, N.A.H., van Vliet, P.H.N., Aarts, F., Harssema, H. and Brunekreef, B. (2001) Assessment of Exposure to Traffic Related Air Pollution of Children Attending Schools near Motorways. Atmospheric Environment, 35, 38753884. http://dx.doi.org/10.1016/S1352-2310(01)00144-3

[31] Rojas-Bracho, L., Suh, H.H., Oyola, B. and Koutrakis, P. (2002) Measurements of Children's Exposures to Particles and Nitrogen Dioxide in Santiago, Chile. Science of the Total Environment, 287, 249-264. http://dx.doi.org/10.1016/S0048-9697(01)00987-1

[32] Mukherjee, A.K., Bhattacharya, S.K., Ahmed, S., Roy, S.K., Roychowdhury, A. and Sen, S. (2003) Exposure of Drivers and Conductors to Noise, Heat, Dust and Volatile Organic Compounds in the State Transport Special Buses of 
Kolkata City. Transportation Research, D8, 11-19. http://dx.doi.org/10.1016/S1361-9209(02)00015-9

[33] Gulliver, J. and Briggs, D.J. (2004) Personal Exposure to Particulate Air Pollution in Transport Microenvironments. Atmospheric Environment, 38, 1-8. http://dx.doi.org/10.1016/j.atmosenv.2003.09.036

[34] Kaur, S., Nieuwenhuijsen, M.J. and Colvile, R.N. (2005) Pedestrian Exposure to Air Pollution along a Major Road in Central London, UK. Atmospheric Environment, 39, 7307-7320. http://dx.doi.org/10.1016/j.atmosenv.2005.09.008

[35] Dons, E., Panis, L., Poppel, M., Theunis, J., Willems, H., Torfs, R. and Wets, G. (2011) Impact of Time-Activity Patterns on Personal Exposure to Black Carbon. Atmospheric Environment, 45, 3594-3602. http://dx.doi.org/10.1016/j.atmosenv.2011.03.064

[36] Steinle, S., Reis, S. and Sabel, C. (2013) Quantifying Human Exposure to Air Pollution-Moving from Static Monitoring to Spatio-Temporally Resolved Personal Exposure Assessment. Science of the Total Environment, 443, $184-193$. http://dx.doi.org/10.1016/j.scitotenv.2012.10.098

[37] Loth, K. and Ashmore, M. (1994) Assessment of Personal Exposure to Air Pollution. Clean Air, 24, 114-122.

[38] Letz, R., Ryan, P.B. and Spengler, J.D. (1984) Estimated Distribution of Personal Exposure to Respirable Particles. Environmental Monitoring Assessment, 4, 351-359. http://dx.doi.org/10.1007/BF00394173

[39] Ashmore, M. and Dimitroulopoulou, C. (2009) Personal Exposure of Children to Air Pollution. Atmospheric Environment, 43, 128-141. http://dx.doi.org/10.1016/j.atmosenv.2008.09.024

[40] An, X., Hou, Q., Li, N. and Zhai, S. (2013) Assessment of Human Exposure Level to $\mathrm{PM}_{10}$ in China. Atmospheric Environment, 70, 376-386. http://dx.doi.org/10.1016/j.atmosenv.2013.01.017

[41] Wallace, L.A. (1989) Major Sources of Benzene Exposure. Environmental Health Perspectives, 82, 165-169. http://dx.doi.org/10.1289/ehp.8982165

[42] Chan, C., Spengler, J., Ozkaynak, H. and Lefkopoulou, M. (1991) Commuter Exposures to VOCs in Boston, Massachusetts. Journal of the Air \& Waste Management Association, 41, 1594-1600. http://dx.doi.org/10.1080/10473289.1991.10466955

[43] Steinemann, A. (2004) Human Exposure, Health Hazards, and Environmental Regulations. Environmental Impact Assessment Review, 24, 695-710. http://dx.doi.org/10.1016/j.eiar.2004.06.002 
Scientific Research Publishing (SCIRP) is one of the largest Open Access journal publishers. It is currently publishing more than 200 open access, online, peer-reviewed journals covering a wide range of academic disciplines. SCIRP serves the worldwide academic communities and contributes to the progress and application of science with its publication.

Other selected journals from SCIRP are listed as below. Submit your manuscript to us via either submit@scirp.org or Online Submission Portal.
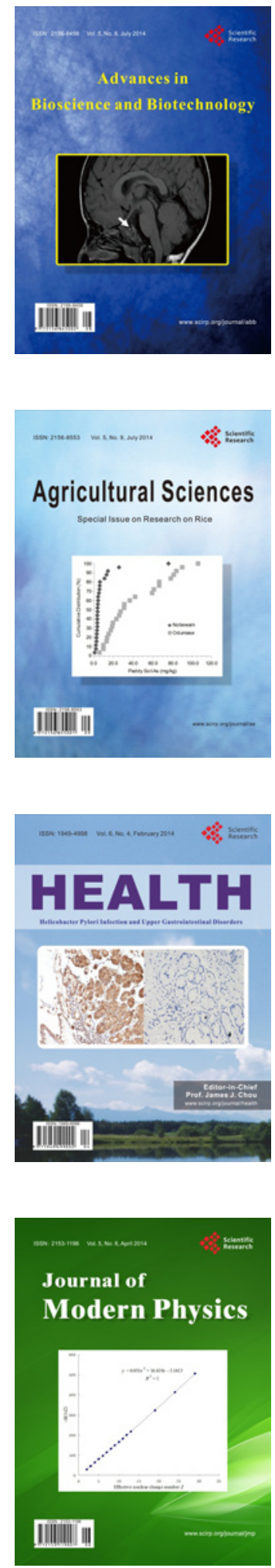
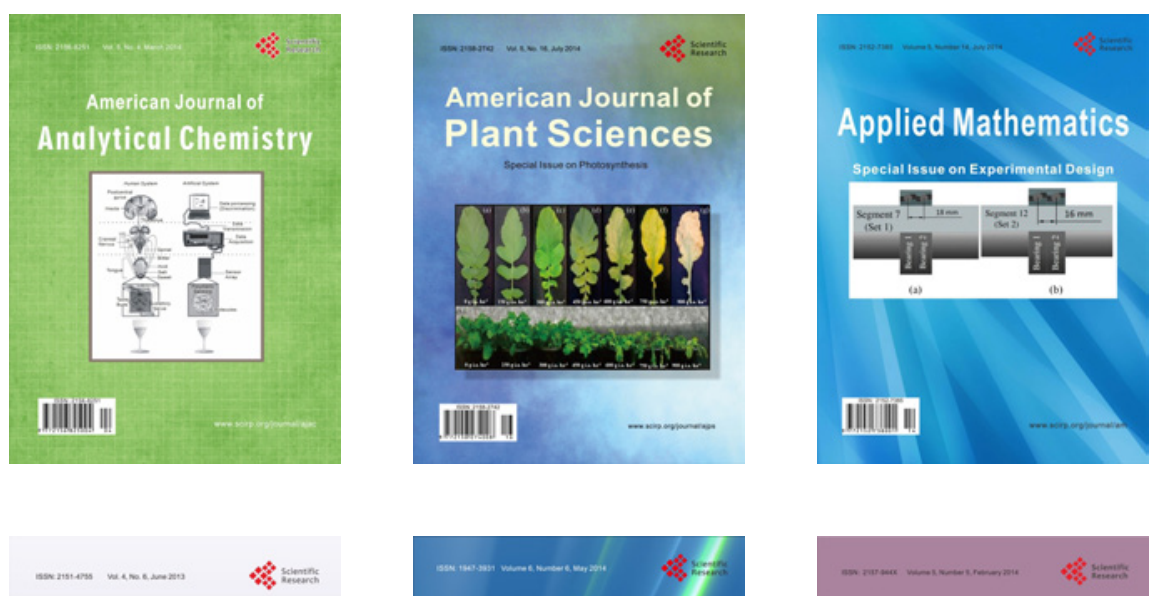

Creative Education
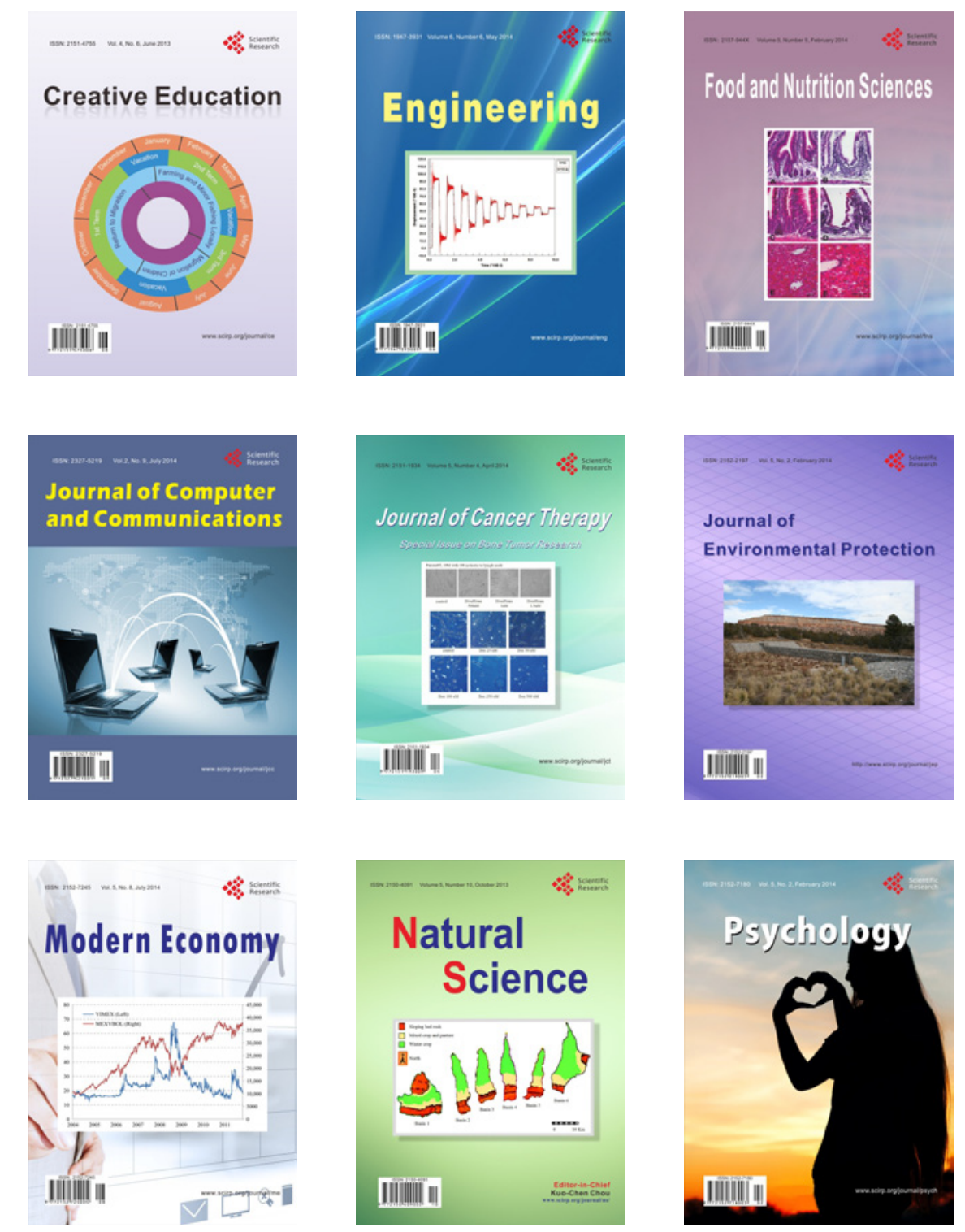